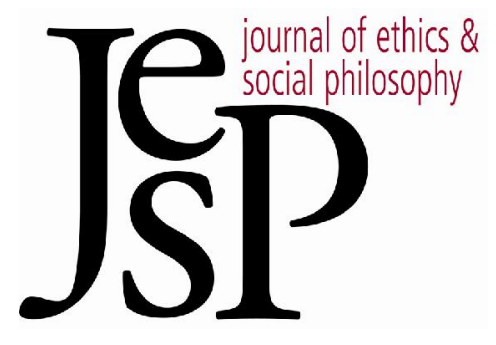

\title{
COMMENT ON RAZ
}

BY R. JAY WALLACE

Journal of Ethics\& Social Philosophy

SYMPOSIUM I | DECEMBER 2005

URL: WWW.JESP.ORG

COPYRIGHT @ R. JAY WALLACE 2005 


\section{COMMENT ON RAZ}

By R. Jay Wallace

1

$\mathrm{N}$ "THE MYTH OF INSTRUMENTAL RATIONALITY," Joseph Raz defends the view that there is no such thing as distinctively instrumental rationality.1 There are instrumental reasons of a kind, insofar as our reasons to pursue ends are e $e$ ipso reasons to do things that would facilitate the attainment of those ends. There are, in addition, certain virtues of agency, in the sense of dispositions and patterns of thought that generally enhance our capacity to achieve what we set out to do, and a tendency to take the necessary means to one's intended ends may be counted among these admirable tendencies. But there is no strictly rational requirement to take means that are necessary relative to one's chosen ends.

I find much to agree with in Raz's treatment of this complex and important topic. On the central point, however, I also find myself stubbornly clinging to the idea that there is a rational requirement to take the means that are necessary for the successful realization of one's intentions or plans. My own favored account of this requirement attempts to do justice to two dimensions of instrumental rationality. ${ }^{2}$ First, the requirement applies even in cases in which we are acting in pursuit of ends that we do not ourselves fully endorse. Second, it applies in a way that involves a kind of rational pressure to revise our attitudes. We feel and respond to this pressure when we adopt necessary means to our ends, or give up our ends upon realizing that we are not willing to take the means that are necessary for their attainment. My conviction is that we can do justice to these twin features of instrumental rationality only by tracing the instrumental principle to requirements of theoretical rationality concerning the coherence of our beliefs (including the beliefs that are bound up with the intention to pursue a given end). These are requirements whose force is familiar to us as believers, insofar as we feel and respond to a rational pressure to revise our beliefs when we recognize them to be inconsistent. Furthermore, the theoretical source of the rational pressure to revise inconsistent beliefs renders it applicable to situations in which we are acting in pursuit of ends that we do not fully endorse.

On my account, then, agents who fail to intend the means they believe necessary relative to ends they intend to achieve are subject to inconsistent beliefs. But Raz's paper raises a challenging question about this conclusion: what is wrong with having beliefs that are in this way incoherent? The set of beliefs we hold may well turn out to contain many latent inconsistencies, but this fact alone generates no particular rational pressure in the direction of making specific revisions. That our beliefs are

1 Joseph Raz, "The Myth of Instrumental Rationality," Journal of E thics and Social Philosophy (2005), www.jesp.org vol. 1, no. 1.

2 "Normativity, Commitment, and Instrumental Reason," Philosophers' Imprint 1, no. 3 (D ecember 2001), http:/ / www.philosophersimprint.org/ 001003. 
inconsistent entails that not everything we believe can be true, but this in itself poses no special problem so long as we remain in the dark about where in our network of beliefs specific falsehoods may lie.

Of course, in the case of instrumental irrationality we can, it would seem, locate the falsehood in our beliefs. We believe the following three propositions, and know that they cannot together be true:

(1) It is possible that I do X.

(2) It is possible that I do X only if I also intend to do Y.

(3) I do not intend to do Y.

Raz objects that the appeal to falsehood in this complex of beliefs fails to illuminate what is undesirable about the failure to take necessary means to one's chosen ends. In particular, he suggests, we need an explanation of the undesirability of this false belief "that explains why the so-called principle of instrumental rationality is one of the standards that determine well-functioning deliberative processes." 3 But the appeal to false beliefs does not illuminate the role of the instrumental principle as a norm of deliberative good functioning. Thus, someone who intends to perform an action that it is in fact impossible for them to perform might end up wasting limited resources of time and energy in an essentially fruitless pursuit. But if such a person happens to be instrumentally irrational, they will spare themselves this fate. They may be subject to a false belief, but in the present context this actually seems to be an advantage, something that is conducive to their overall good functioning as an agent.

Of course, it is an important desideratum for the position I favor that instrumental requirements operate even in cases in which we are in other respects falling short of ideals of agency. The requirements at issue therefore cannot be seen as having their source in such ideals. I trace them instead to theoretical ideals concerning our good functioning as believers, supposing that ideals of this kind are capable of grounding requirements that remain in force independently of whether compliance with them is, on a particular occasion, conducive to our realization of the good.

Raz disagrees, explaining the apparent force of instrumental rationality by appeal to general standards of effective agency. "If you are prone to instrumental irrationality, you are less likely to achieve your ends, whatever they are." 4 A certain practiced knack for taking the necessary means to our ends is an important executive capacity, one that any successful agent will need to acquire, and our sense that we are irrational or defective when we fail to take the necessary means to our ends derives from the general role of this executive capacity in relation to deliberative good functioning. I think Raz is correct to emphasize the role of instrumental rationality as part of our good functioning as agents. ${ }^{5}$ But this point does

${ }^{3}$ See Raz, "The Myth of Instrumental Rationality," p. 17.

4 Ibid.

${ }^{5} \mathrm{~A}$ similar view is defended by Michael Bratman, in Intention, Plans, and Practical Reason (Cambridge, Mass.: Harvard University Press, 1987), at e.g. p. 51 - a source upon which Raz draws. 
not suffice to account for the full normative significance of the instrumental principle.

On Raz's account, that principle serves to specify a standard of excellence in agency, defining what we might think of as a kind of allpurpose executive virtue. But this tums the instrumental principle into an evaluative ideal, one that is not sufficiently anchored in the deliberative perspective of the agent. Someone who believes that a given means is necessary relative to an end that they intend to achieve will experience an immediate rational pressure to revise their attitudes. This pressure cannot derive from the fact that they will fail to exhibit an executive virtue if they do not revise their attitudes. For one thing, the agent may not be aware that the principle of instrumental rationality defines a standard of executive virtue. Indeed, there are probably very few of us who think of the tendency to take necessary means to one's ends in these basic terms, as an executive virtue. Furthermore, even if we would acknowledge this description upon reflection, it is not something we tend to focus on when we experience the pressure to revise our attitudes in accordance with the instrumental principle. Nor would it help particularly in this context to focus on the standing of one's tendency to adopt necessary means as an executive virtue, since doing so would not necessarily translate into any particular rational requirement to which the agent would feel pressure to respond. (A kratic agents in particular would probably not care very much about the fact that they are failing to exhibit excellence in agency, given that they are not responsive to the acknowledged badness of their own immediate ends.)

My claim is that we can make sense of a kind of rational pressure to which even akratic agents are susceptible by appealing to the apparent conflict in the beliefs to which agents are subject when they fail to adopt means that they believe to be necessary relative to their intended ends. But Raz apparently doubts that there are genuine theoretical requirements that give us concrete guidance in situations of this kind. He notes that "nothing follows about what we ought to do or believe and when we should suspend belief from the mere knowledge that a set of beliefs contains a contradiction." 6 The fact that some subset of one's beliefs is inconsistent is no reason in itself to change the beliefs in the inconsistent set. This may be true as far as it goes, but it underestimates the extent to which awareness of localized inconsistency in belief can generate rational pressures on the believer. Even if I do not immediately know which of my inconsistent beliefs to revise, the fact that they are inconsistent is at least a pro tanto reason to reassess the credentials of the items in the inconsistent set. Furthermore, in the particular case at issue, there is a special feature of at least one of these problematic beliefs that simplifies the process of revision in response to acknowledged local inconsistency. Thus belief (3) in the above set is a belief about my own intentions; the truth to which it is answerable is a matter that is directly subject to my volitional control. In this unusual situation, I can restore coherence to the problematic set of beliefs by adjusting my intentions regarding the neces-

${ }^{6} \mathrm{Raz}$, "The Myth of Instrumental Rationality," p. 20. 
sary means, and thereby giving myself grounds for revising belief (3). If I nevertheless refuse to adjust my attitudes in this way, and retain my conviction that the means is really necessary, then I have no option but to revise belief (1), which in turn precludes me from continuing to intend the original end.

It might be thought that forming an intention to take the means in response to this kind of inconsistency fails to do justice to the nature of belief, which is answerable to independent facts of the matter about the way things are. I should revise belief (3), that I do not intend to take the means, because I have now formed such an intention; but then it seems I must have had some independent reason for adjusting my intentions in this way before I can revise my beliefs in the matter. 7 agree that if belief (3) is to be revised, the only way to achieve this compatibly with the nature of belief as answerable to the truth is to revise one's intention first, by deciding or resolving to take the means. It does not follow, however, that there needs to be an independent or prior ground for forming this intention (independent, that is, from considerations about the consistency of one's beliefs). In the case at issue, where the belief in question is about a matter that is directly under my own control, the rational pressure that leads me to form an intention might well be the fact that I will thereby bring about coherence in a set of attitudes that includes a belief about my own intentions.

R. Jay Wallace

D epartment of Philosophy

University of California, Berkeley

rjw@ berkeley.edu

7 See John Brunero, "Two Approaches to Instrumental Rationality and Belief Consistency," Journal of E thics and Social Philosophy (April 2005), vol. 1, no. 1, www.jesp.org, p. 4. 